\title{
AN APPROACH TO ENHANCE THE SOLUBILITY OF RIFAPENTINE BY SOLID DISPERSION TECHNIQUE USING HYDROPHILIC CARRIERS
}

\author{
*Pathak Vinay Madhav ${ }^{1}$, Rawat Swati ${ }^{1}$, Sharma Y.P. ${ }^{1}$, Priyanshu Jain ${ }^{2}$, Sagar B Thoke ${ }^{1}$ \\ ${ }^{1}$ Department of Pharmaceutics, S.N.D. College of Pharmacy, Babhulgaon, Yeola, Nashik, India \\ ${ }^{2}$ Department of Pharmaceutical Chemistry, S.N.D. College of Pharmacy, Babhulgaon, Yeola, Nashik, India \\ *Corresponding Author's E mail: realpharmaworld@ gmail.com, vinay.mp.pathak@ gmail.com, Contact no.: 9403466286, 9657945056
}

\begin{abstract}
The aim of this present work was to improve the dissolution profile of Rifapentine (RPT) using solid dispersions technique with PVP K-30 or HPMC as the carrier, in different ratios of 1:1, 1:2, 1:3, 1:4, 1:5 by the kneading method and solvent evaporation method. For the purpose of comparison, another formulation was prepared by the method of physical mixture with the drug and carrier weight ratios of same. The prepared solid dispersions (SDs) were optimized on the basis of evaluation of Solubility, percentage drug release rate and percentage drug content. Optimized formulation is then characterized by Fourier Transform Infrared Spectroscopy (FTIR), Powder X-ray Diffraction (XRD), Differential Scanning Calorimetry (DSC), Particle size analysis and Scanning Electron Microscopy (SEM) in order to ascertain any physicochemical interactions between the drug and carrier that could affect the dissolution profile of the drug. The dissolution studies were conducted for pure Rifapentine and all the formulated solid dispersions. All the solid dispersions prepared by kneading method and solvent evaporation method showed an enhanced dissolution profile of Rifapentine, as compared to that of pure drug alone but among them all, the solid dispersion prepared with PVP-K30 by solvent evaporation method in 1:3 ratio showed better enhancement of solubility and dissolution rate.
\end{abstract}

Keywords: Solid dispersion, Rifapentine, solvent evaporation method, Kneeding method, PVP K-30, HPMC.

\section{INTRODUCTION}

Rifapentine is a semisynthetic rifamycin derivative from the piperazinyl hydrazone class with a microbiologic profile similar to that of rifampin. ${ }^{1}$ Its structure differs from that of rifampin by the presence of a cyclopentyl ring instead of a methyl group at the piperazinyl moiety. ${ }^{2}$ The chemical formula of rifapentine is rifamycin, 3-[[(4cyclopentyl- 1-piperazinyl)imino] methyl]. Its molecular formula is $\mathrm{C}_{47} \mathrm{H}_{64} \mathrm{~N}_{4 \mathrm{O}}$ and its molecular weight is approximately $877 \mathrm{Da}^{3}$

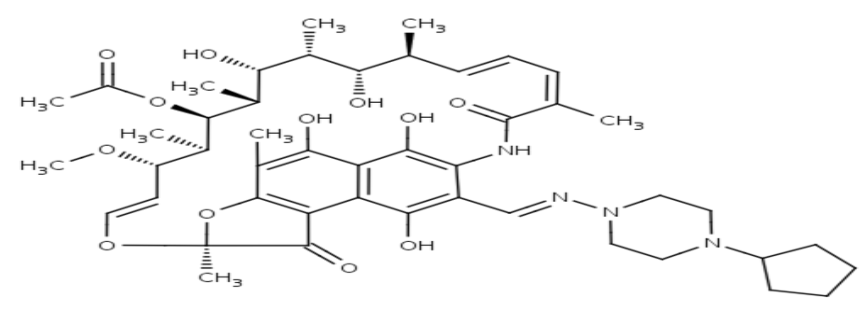

Fig. 1 Structure of Rifapentine ${ }^{4}$

Rifapentine was first synthesized in 1965 by the same company that produced rifampin. The drug was approved by the Food and Drug Administration (FDA) in June 1998. It is synthesized in one step from rifampicine. ${ }^{5}$ Rifapentine is approved for the treatment of tuberculosis in the US. The drug is also used in China. Rifapentine has a long half-life which allows for once-weekly administration. When administered twice weekly during the intensive phase and once weekly during the continuation phase, rifapentine has demonstrated efficacy in the treatment of pulmonary tuberculosis in immunocompetent patients. ${ }^{6}$

Rifapentine has a potential advantage over rifampcin because its long half-life (13 hours compared with 3 hours) could allow for less frequent dosing. Aqueous solubility of any therapeutically active substance is a key property as it governs dissolution, absorption and thus the efficacy in vivo. Currently only $8 \%$ of new drug candidates have both high solubility and permeability. Solubilization of poorly aqueous soluble drug forms an important activity in formulation process. For many formulation scientists in the big pharma companies, it became clear in the early 1990s that they had to learn and invest much more into solubilizing/enhancing technologies like complexation of drug candidates with cyclodextrins, microemulsion (SMEDDS formulations), nanosuspension or solid dispersion formulation technologies having the potential to enhance bioavailability. ${ }^{7}$ This study seeks to investigate kneading method, physical mixture, and solvent evaporation as a method for the preparation of these binary systems as well as their solid state characterization by employing analytical tools such as Fourier Transform infrared (FTIR), Powder X-ray Diffraction (XRD), Differential Scanning Calorimetry (DSC), particle size analysis and Scanning electron microscopy (SEM).

\section{MATERIAL AND METHODS}

Rifapentine was obtained from Lupin Pharmaceuticals, Aurangabaad, as a gift sample. PVP-K30, HPMC and methanol were purchased from S.D.fine chemicals limited, Mumbai. All the carriers used were of analytical grade.

\section{Methods ${ }^{8-10}$}

The Preparation of drug-PVP-K30 and drug-HPMC solid dispersions were prepared by kneeding and solvent evaporation Techniques which are described below: (Table 1) 
Table 1: Formulation code of Solid Dispersion for different method of preparation

\begin{tabular}{|c|c|c|c|c|}
\hline \multirow{2}{*}{ Sr. No. } & \multirow{2}{*}{ Name of method } & \multirow{2}{*}{ Drug : polymer ratio } & \multicolumn{2}{|c|}{ Solid dispersions } \\
\hline & & & With PVP-K30 & With HPMC \\
\hline 1 & Physical mixtures & $1: 1$ & PM1 & PM2 \\
\hline \multirow{5}{*}{2} & \multirow{5}{*}{ Kneeding method } & $1: 1$ & SP1 & SH1 \\
\hline & & $1: 2$ & SP2 & SH2 \\
\hline & & $1: 3$ & SP3 & SH3 \\
\hline & & $1: 4$ & SP4 & SH4 \\
\hline & & $1: 5$ & SP5 & SH5 \\
\hline \multirow{5}{*}{3} & \multirow{5}{*}{ Solvent evaporation method } & $1: 1$ & SP6 & SH6 \\
\hline & & $1: 2$ & SP7 & SH7 \\
\hline & & $1: 3$ & SP8 & SH8 \\
\hline & & $1: 4$ & SP9 & SH9 \\
\hline & & $1: 5$ & SP10 & SH10 \\
\hline
\end{tabular}

\section{Physical Mixture}

Physical mixtures were prepared by simple blending in a glass mortar of accurately weighed quantities of $\operatorname{drug}(\mathrm{s})$ and carrier(s) for about one hour in ratio of $1: 1$ and passed through sieve no.85 and stored in desiccator over fused calcium chloride.

\section{Kneading Method}

Separate sets of mixture of HPMC-Rifapentine and PVPK30-Rifapentine were weighed accurately in specified quantity $(1: 1,1: 2,1: 3,1: 4$ and 1:5). The mixtures were wetted with water: methanol $(50 \% \mathrm{v} / \mathrm{v})$ and kneaded thoroughly for $45 \mathrm{~min}$ in glass mortar. Further, the products was dried at $40^{\circ} \mathrm{C}$ for $48 \mathrm{hr}$, passed through sieve No.85 and stored in a desiccator over fused calcium chloride.

\section{Solvent-Evaporation method}

The Accurately weighed amount of Drug and HPMC (1:1, $1: 2,1: 3,1: 4$ and 1:5) were dissolved in methanol to get a clear solution and same preparation for drug and PVP-K30 ratios. The resulting solution was stirred at ambient temperature until complete evaporation of the solvent occurred. The resulting preparation were kept in desiccators for the least $48 \mathrm{hr}$ and then grounded in a glass mortar for size reduction and passed through sieve no.85 and stored in desiccators over fused calcium chloride.

\section{Characterization of solid dispersion ${ }^{11-13}$}

\section{Drug Content Determination}

Powdered solid dispersion and physical mixture equivalent to $10 \mathrm{mg}$ Rifapentine drug accurately weighed and transferred to $100 \mathrm{ml}$ volumetric flask. About $20 \mathrm{ml}$ water added and flask shaken gently to dissolve complete residue. Then make up volume with water which gives resulting solution of $100 \mu \mathrm{g} / \mathrm{ml}$. $1 \mathrm{ml}$ of resulting solution was taken in $10 \mathrm{ml}$ volumetric flask and volume was make up with water. The absorbance of this solution was taken at $476.5 \mathrm{~nm}$ in UV spectrophotometer. And drug content was determined.

\section{Solubility determination}

The apparent solubility of Rifapentine drug and solid dispersions were determined in distilled water at $37^{\circ} \mathrm{C}$. Excess amount of Rifapentine solid dispersion was added to $10 \mathrm{ml}$ of solvent in glass vials with rubber closers. Then the vials were kept on a shaker incubator maintained at 37 $\pm 0.5^{\circ} \mathrm{C}$ for $24 \mathrm{~h}$. After shaking, the vials were kept in an incubator at $37 \pm 0.5^{\circ} \mathrm{C}$ for equilibrium for $12 \mathrm{~h}$. The solution was then filtered through whatman no. 4 filter and the filtrate was assayed spectrophotometrically at 476.5 nm.

\section{In vitro Dissolution Studies}

An ELECTROLAB dissolution test apparatus USP Type II (Paddle) at rotation speed of $50 \mathrm{rpm}$ was used for the study. Dissolution of the drug and samples was carried out on an equivalent of $600 \mathrm{mg}$ of the Rifapentine, 0.1 N HCL was used as dissolution media. The volume and temperature of the dissolution media were $900 \mathrm{ml}$ and $37 \pm$ $0.20 \mathrm{C}$, respectively. After fixed time intervals, $5 \mathrm{ml}$ of samples were withdrawn and sink condition was maintained. These samples were assayed through ultraviolet absorbance measurement at $478 \mathrm{~nm}$ using UVVisible Spectrophotometer (Chemito-2600) by an analytically validated method $(\mathrm{r} 2=0.995$ and $\mathrm{y}=$ $0.005 \mathrm{X}+0.02$ ). The samples were estimated for amount of Rifapentine dissolved by measuring their absorbance at $478 \mathrm{~nm}$. Samples were taken at time interval of 5, 15, 30, 45, 60, 75, $90 \mathrm{~min}$.

From the calculations the highest release showing solid dispersion was optimized.

\section{Infrared Spectroscopy}

IR spectra of drug as well as optimized solid dispersion were obtained using BRUKER FTIR. Drug and optimized solid dispersion were analyzed by IR spectral studies. In this method, the drug sample was scanned in the region of 400-4000 cm-1.

\section{Particle Size Determination}

Particle size analyses of plain drug as well as optimized solid dispersion were carried out with MASTERSIZER 2000 of Malvern. Sample was scanned for 0.1 to $3000 \mu \mathrm{m}$ size of particles.

\section{DSC analysis}

The DSC study was performed on a Mettler Toledo DSC $822 \mathrm{e}$ differential scanning calorimeter with thermal analyzer. Accurately weighed sample (about $2 \mathrm{mg}$ of sample) was placed in sealed aluminum pan, before heating under nitrogen flow $(20 \mathrm{ml} / \mathrm{min})$ at a scanning rate 
of $10^{\circ} \mathrm{C}$ per min from 0 to $200^{\circ} \mathrm{C}$. An empty aluminum pan was used as reference.

\section{X-ray Powder Diffraction (XRD)}

X-ray diffraction analysis was performed using Bruker AXS D8 Advanced model (high beam monochromatic) using $\mathrm{Cu}$ radiation which was generated at $40 \mathrm{Kv}$ and 40 $\mathrm{mA}$ at $1.540600 \mathrm{~A}$. The rate of the scanning was $0.30^{\circ} \mathrm{C}$ /min.

\section{Scanning Electron Microscopy (SEM)}

The samples, an appropriate amount of Rifapentine or Solid dispersion powder or a glass slide with a small drop of the suspension, were fixed on an SEM stub using double-sided adhesive tape and coated with $\mathrm{Au}$ at $50 \mathrm{~mA}$ for 6min through a sputter-coater (KYKY SBC-12, Beijing, China). A scanning electron microscope with a secondary electron detector was used to obtain digital images of the samples at an accelerating voltage of $10 \mathrm{kV}$.

\section{RESULTS}

\section{Standard graph}

Rifapentine was found to be soluble in 0.1N HCL. A simple reproducible method of estimation was carried out in $0.1 \mathrm{~N} \mathrm{HCL}$ ranging from $10-80 \mu \mathrm{g} / \mathrm{ml}$ solutions at 478 nm (Table 2) against the blank the standard graph obtained was linear, with regression coefficient 0.997 and straight line equation $\mathrm{y}=0.005 \mathrm{x}+0.022$. (Figure 2 )

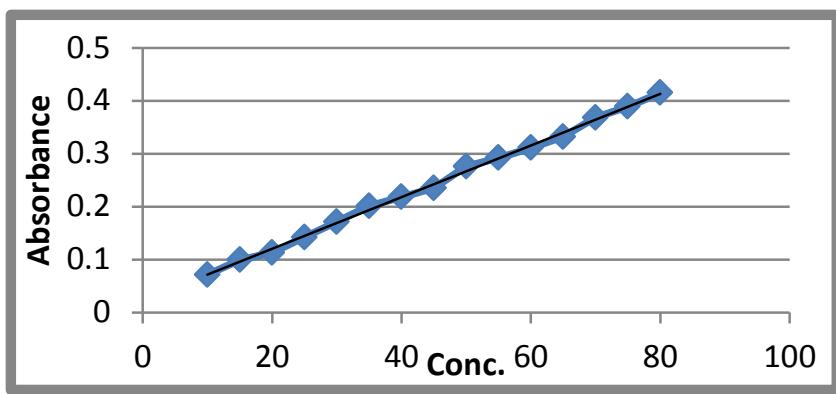

Figure 2: Standard graph of Rifapentine in 0.1N HCL

Table 2: Standard graph of Rifapentine

\begin{tabular}{|c|c|c|}
\hline Sr. No. & Concentration $(\boldsymbol{\mu g} / \mathbf{m l})$ & Absorbance \\
\hline 1 & 10 & 0.071 \\
\hline 2 & 15 & 0.099 \\
\hline 3 & 20 & 0.113 \\
\hline 4 & 25 & 0.142 \\
\hline 5 & 30 & 0.171 \\
\hline 6 & 35 & 0.201 \\
\hline 7 & 40 & 0.218 \\
\hline 8 & 45 & 0.235 \\
\hline 9 & 50 & 0.276 \\
\hline 10 & 55 & 0.292 \\
\hline 11 & 60 & 0.311 \\
\hline 12 & 65 & 0.332 \\
\hline 13 & 70 & 0.368 \\
\hline 14 & 75 & 0.389 \\
\hline 15 & 80 & 0.415 \\
\hline
\end{tabular}

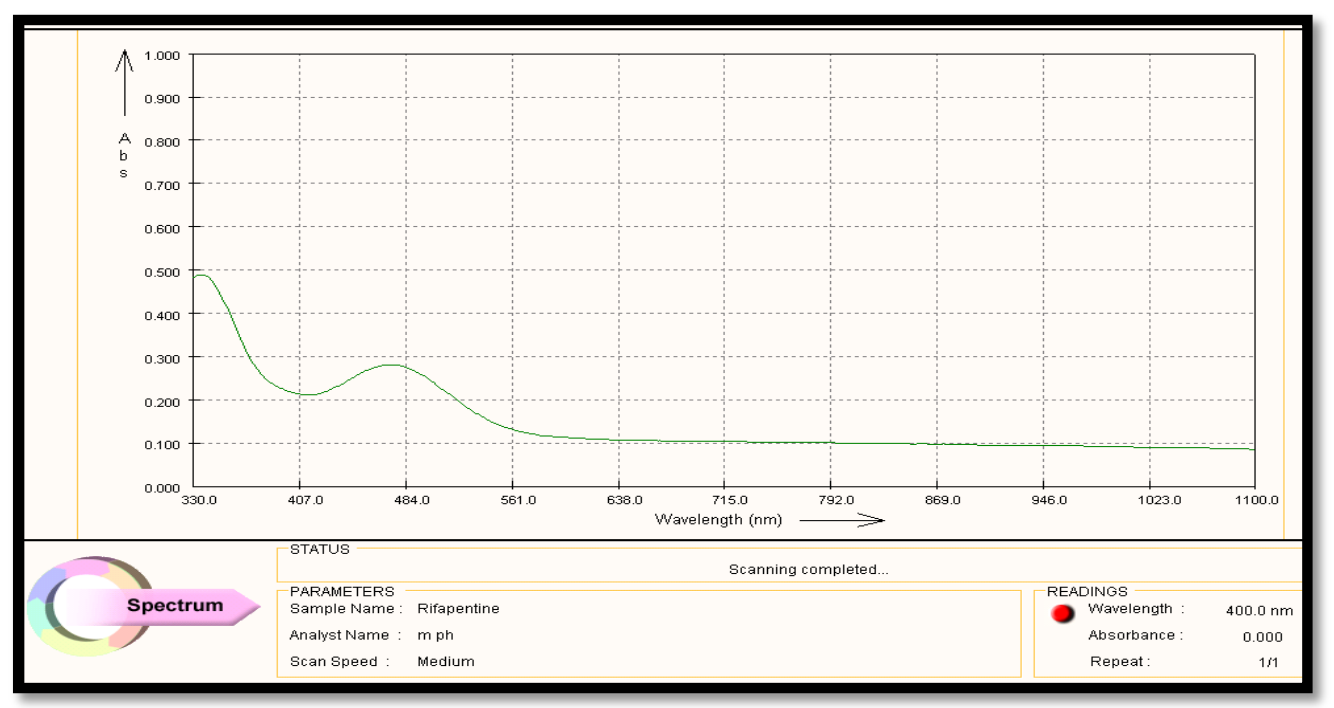

Figure 3: UV-visible absorption spectrum of Rifapentine in 0.1N HCL

Table 3: Standard calibration curve of Rifapentine in distilled water

\begin{tabular}{|c|c|c|}
\hline Sr. No. & Concentration $(\boldsymbol{\mu g} / \mathbf{m l})$ & Absorbance \\
\hline 1 & 10 & 0.078 \\
\hline 2 & 20 & 0.12 \\
\hline 3 & 30 & 0.173 \\
\hline 4 & 40 & 0.231 \\
\hline 5 & 50 & 0.282 \\
\hline 6 & 60 & 0.325 \\
\hline 7 & 70 & 0.373 \\
\hline 8 & 80 & 0.426 \\
\hline
\end{tabular}

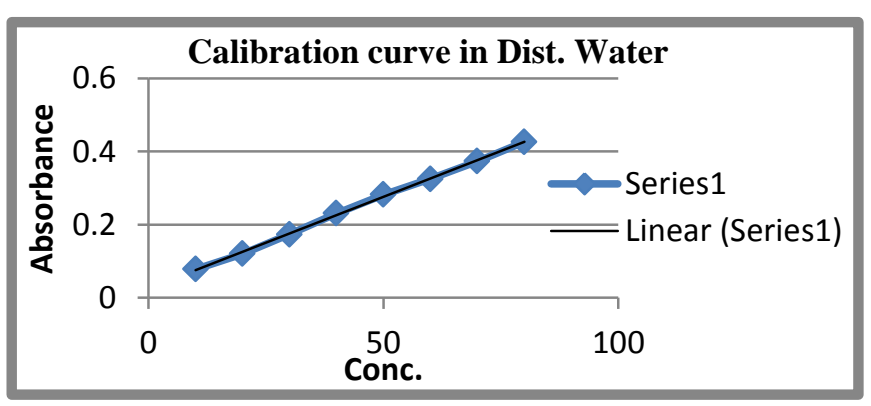

Figure 4: Standard calibration curve of Rifapentine in distilled water 


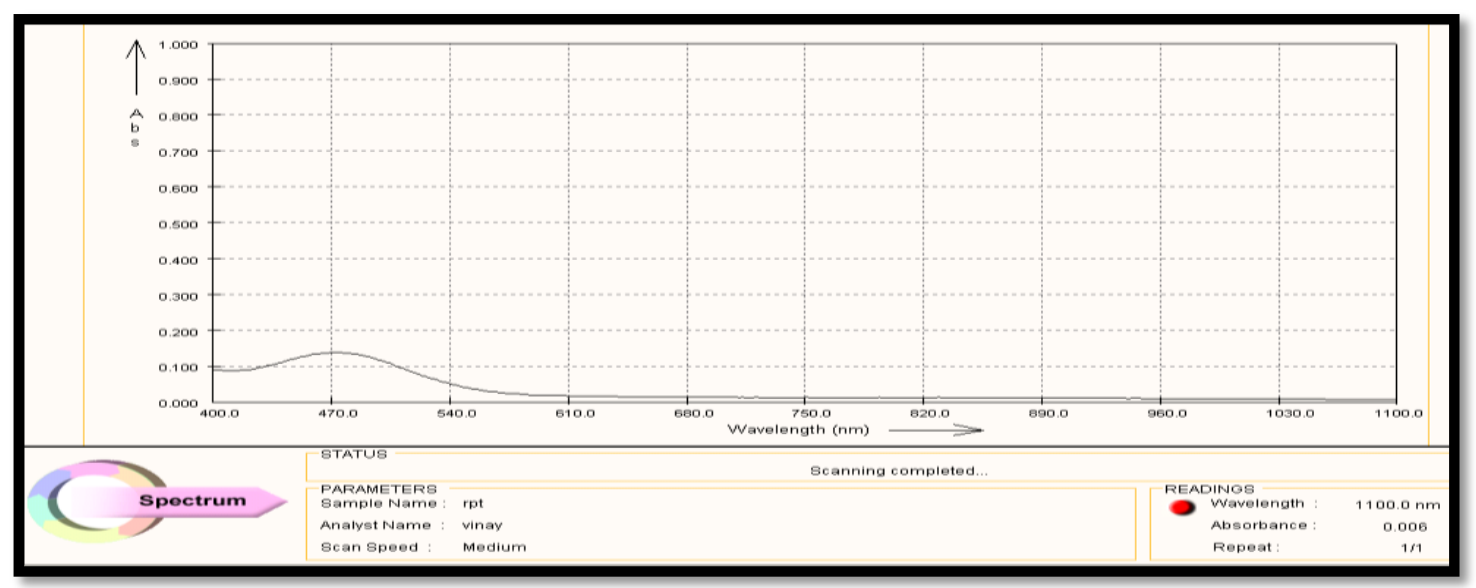

Figure 5: UV-visible absorption spectrum of Rifapentine in water

From the calibration curve equation is given as,

$$
\mathrm{Y}=0.004 \mathrm{X}+0.029
$$

The value of $\mathrm{R}^{2}$ is 0.998 . On the basis of obtained results it was concluded that Rifapentine obeys Beer- Lambert,s law in the range of $10-80 \mathrm{ug} / \mathrm{ml}$.

Table 4: Aqueous solubility, \% Drug Content and \% In vitro release (90 min.) of prepared physical mixtures

\begin{tabular}{|c|c|c|c|c|}
\hline Sr. No. & Batch code & Aqueous solubility (mg/ml) & \% Drug content \pm S.D. & \% In vitro release (90 min.) \\
\hline 1 & Plain drug & $0.623 \pm 0.008$ & - & $38.03 \pm 0.16$ \\
\hline 2 & PM1 & $0.841 \pm 0.002$ & $86.41 \pm 0.05$ & $49.84 \pm 0.21$ \\
\hline 3 & PM2 & $0.752 \pm 0.014$ & $94.32 \pm 0.14$ & $51.80 \pm 0.08$ \\
\hline
\end{tabular}

Table 5: Aqueous solubility, \% drug content and \% vitro drug release (90 min.) of prepared solid dispersions

\begin{tabular}{|c|c|c|c|c|c|c|c|c|}
\hline \multirow{2}{*}{$\begin{array}{c}\text { Sr. } \\
\text { No. }\end{array}$} & $\begin{array}{c}\text { Batch } \\
\text { code }\end{array}$ & $\begin{array}{c}\text { Aqueous } \\
\text { solubility } \\
(\mathbf{m g} / \mathbf{m l})\end{array}$ & $\begin{array}{c}\text { \% drug } \\
\text { content } \pm \\
\text { S.D. }\end{array}$ & $\begin{array}{c}\text { \% vitro drug } \\
\text { release (90 } \\
\text { min.) }\end{array}$ & $\begin{array}{c}\text { Solvent evaporation method } \\
\text { Batch } \\
\text { code }\end{array}$ & $\begin{array}{c}\text { Aqueous } \\
\text { solubility } \\
\text { (mg/ml) }\end{array}$ & $\begin{array}{c}\text { \% drug } \\
\text { content } \pm \\
\text { S.D. }\end{array}$ & $\begin{array}{c}\text { \% vitro drug } \\
\text { release (90 } \\
\text { min.) }\end{array}$ \\
\hline 1 & SP1 & $1.04 \pm 0.002$ & $90.48 \pm 0.208$ & 81.71 & SP6 & $2.31 \pm 0.016$ & $89.28 \pm 0.172$ & 88.79 \\
\hline 2 & SP2 & $1.71 \pm 0.004$ & $86.26 \pm 0.046$ & 84.86 & SP7 & $3.24 \pm 0.003$ & $92.54 \pm 0.027$ & 91.15 \\
\hline 3 & SP3 & $4.51 \pm 0.013$ & $89.71 \pm 0.291$ & 84.07 & SP8 & $6.34 \pm 0.002$ & $87.71 \pm 0.081$ & 93.91 \\
\hline 4 & SP4 & $2.86 \pm 0.017$ & $94.81 \pm 0.163$ & 88.79 & SP9 & $5.47 \pm 0.015$ & $94.83 \pm 0.401$ & 90.36 \\
\hline 5 & SP5 & $4.59 \pm 0.001$ & $90.32 \pm 0.052$ & 87.22 & SP10 & $4.78 \pm 0.002$ & $95.01 \pm 0.041$ & 88.79 \\
\hline 6 & SH1 & $0.94 \pm 0.001$ & $92.49 \pm 0.423$ & 79.35 & SH6 & $1.61 \pm 0.042$ & $90.62 \pm 0.147$ & 87.61 \\
\hline 7 & SH2 & $2.31 \pm 0.008$ & $87.08 \pm 0.319$ & 80.92 & SH7 & $2.86 \pm 0.012$ & $87.47 \pm 0.051$ & 88.40 \\
\hline 8 & SH3 & $4.59 \pm 0.016$ & $84.75 \pm 0.041$ & 86.04 & SH8 & $5.71 \pm 0.006$ & $89.83 \pm 0.242$ & 90.36 \\
\hline 9 & SH4 & $2.96 \pm 0.003$ & $91.62 \pm 0.172$ & 87.22 & SH9 & $4.09 \pm 0.013$ & $93.45 \pm 0.071$ & 88.08 \\
\hline 10 & SH5 & $5.10 \pm 0.027$ & $93.38 \pm 0.220$ & 84.86 & SH10 & $5.34 \pm 0.002$ & $92.08 \pm 0.135$ & 87.22 \\
\hline
\end{tabular}

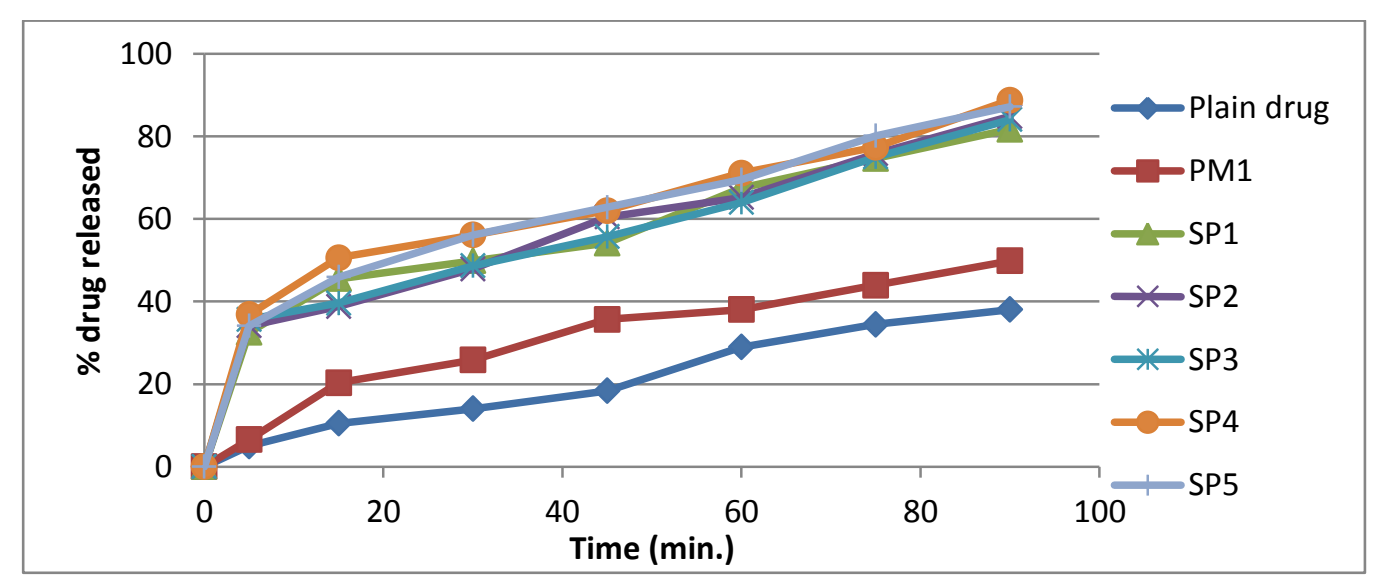

Figure 4: Dissolution profiles of Rifapentine, mixtures of Rifapentine and PVP-K30 and solid dispersions prepared by kneeding method in $0.1 \mathrm{~N} \mathrm{HCl}$ at $37 \pm 0.5^{\circ} \mathrm{C}$ 


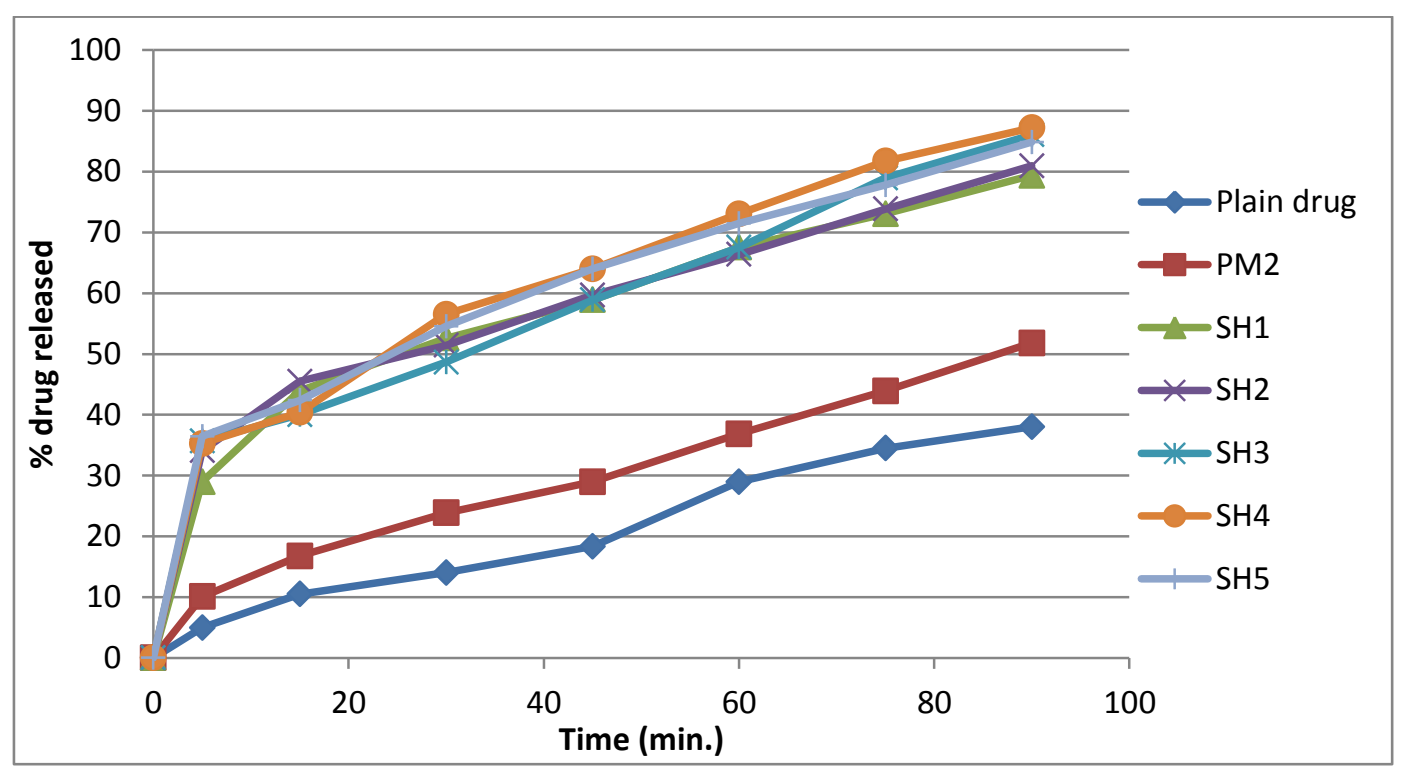

Figure 5: Dissolution profiles of Rifapentine, mixtures of Rifapentine and HPMC and solid dispersions prepared by kneeding method in $0.1 \mathrm{~N} \mathrm{HCl}$ at $37 \pm 0.5^{\circ} \mathrm{C}$

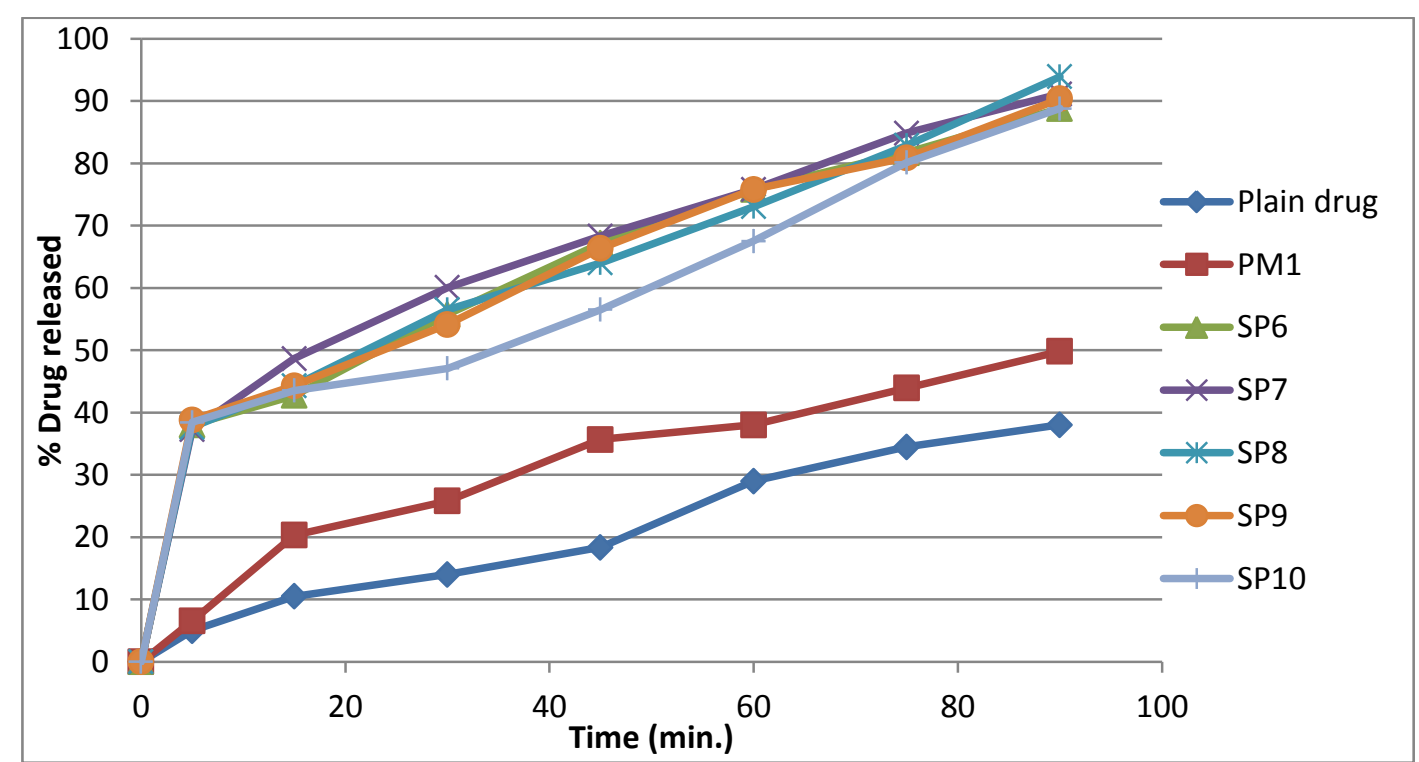

Figure 6: Dissolution profiles of Rifapentine, mixtures of Rifapentine and PVP-K30 and solid dispersions prepared by solvent evaporation method in $0.1 \mathrm{~N} \mathrm{HCl}$ at $37 \pm 0.5^{\circ} \mathrm{C}$

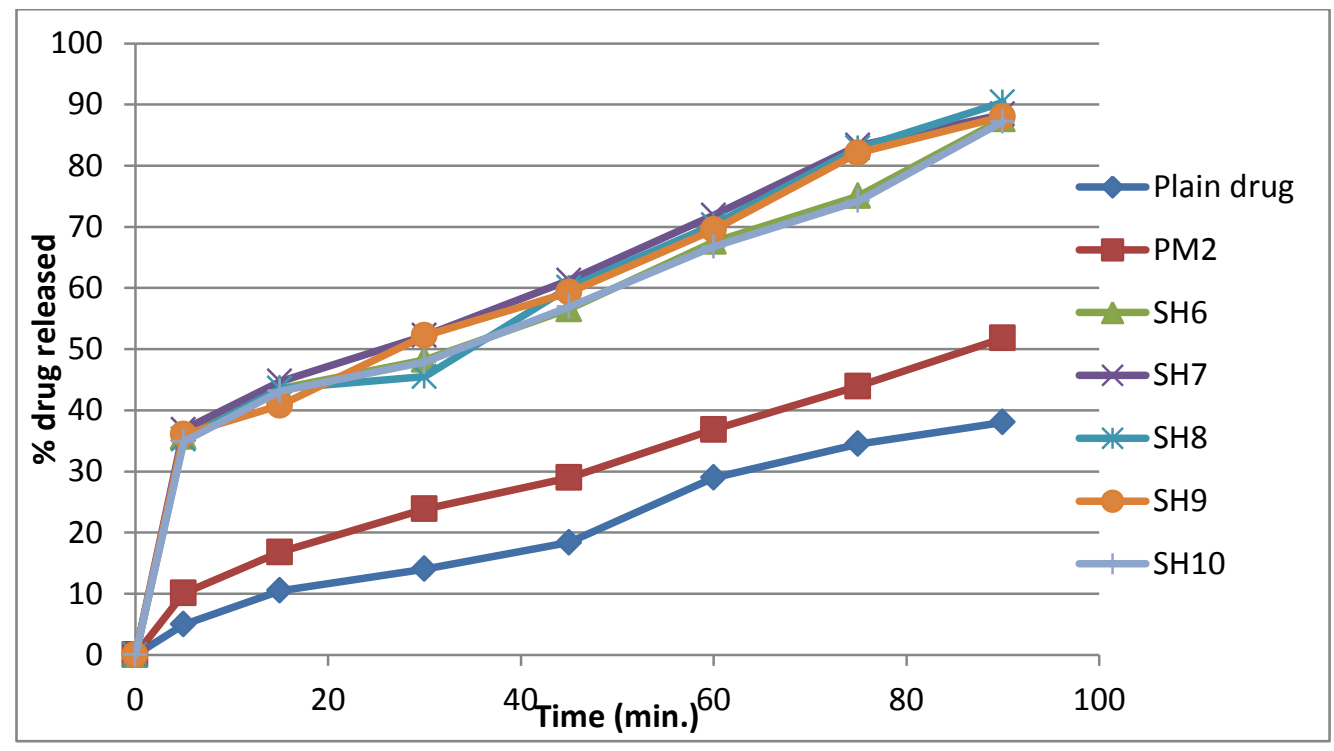

Figure 7: Dissolution profiles of Rifapentine, mixtures of Rifapentine and HPMC and solid dispersions prepared by solvent evaporation method in $0.1 \mathrm{~N} \mathrm{HCl}$ at $37 \pm 0.5^{\circ} \mathrm{C}$ 

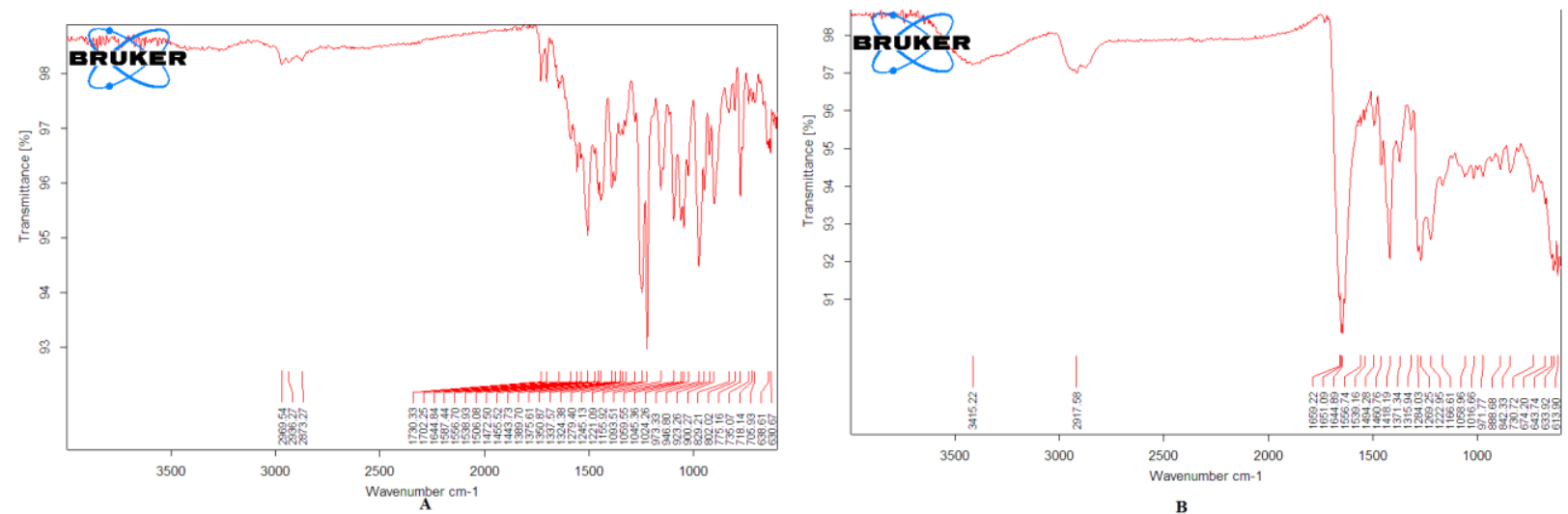

Figure 8: FTIR spectra of Rifapentine bulk drug (A) and SP8 (optimized solid dispersion) (B)
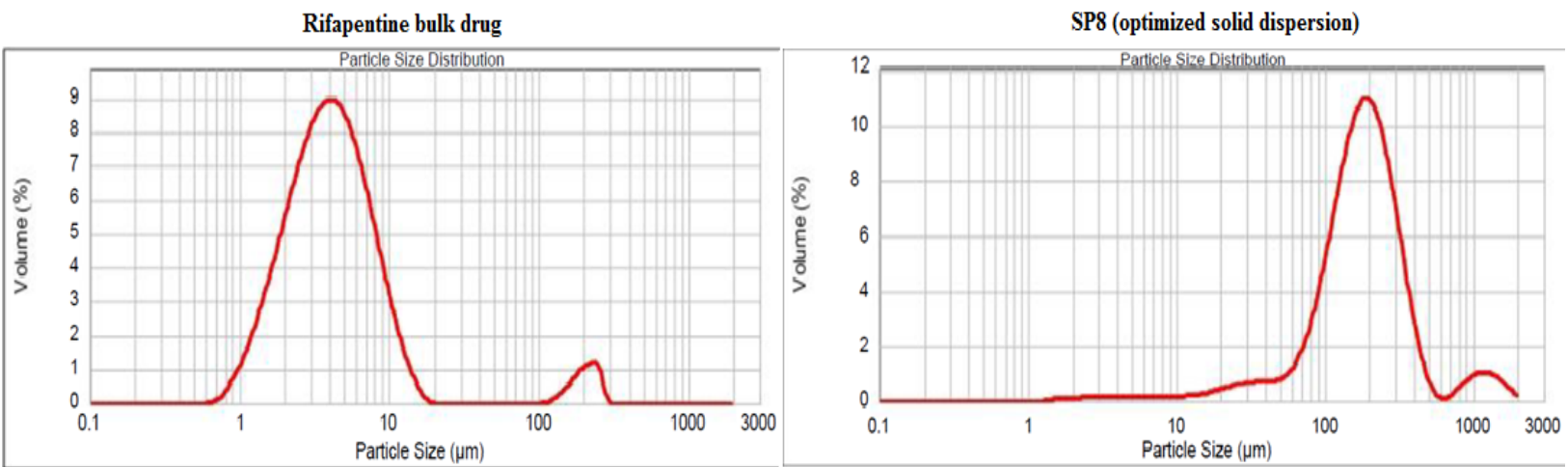

Figure 10: Particle size distribution graph of Rifapentine bulk drug and SP8 (optimized solid dispersion)
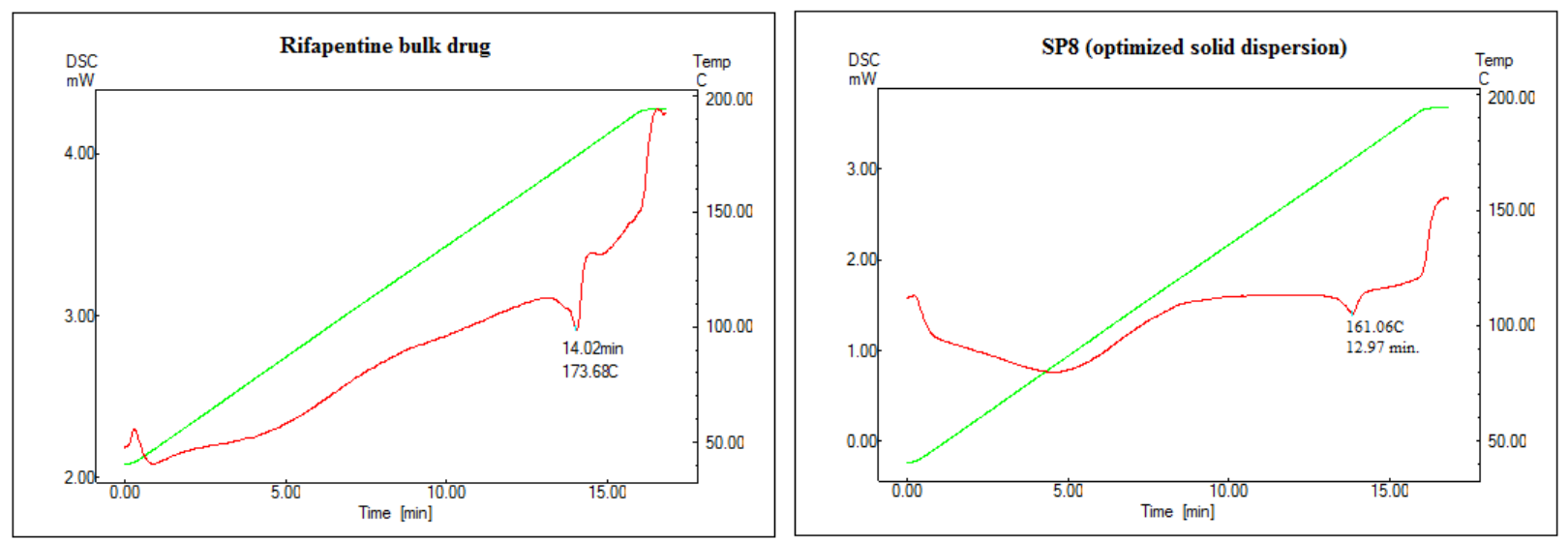

Figure 12: DSC graph of Rifapentine bulk drug and SP8 (optimized solid dispersion)

Rifapentine bulk drug

SP8 (optimized solid dispersion)
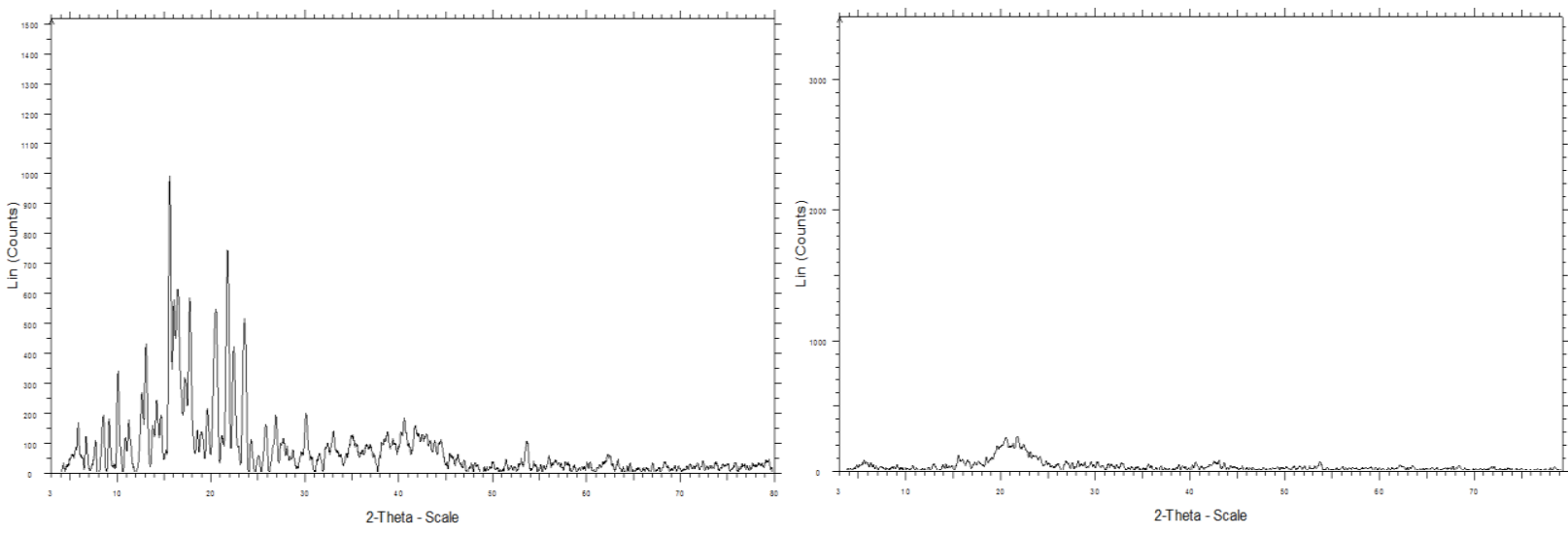

Figure 13: XRD graph of Rifapentine bulk drug and SP8 (optimized solid dispersion) 


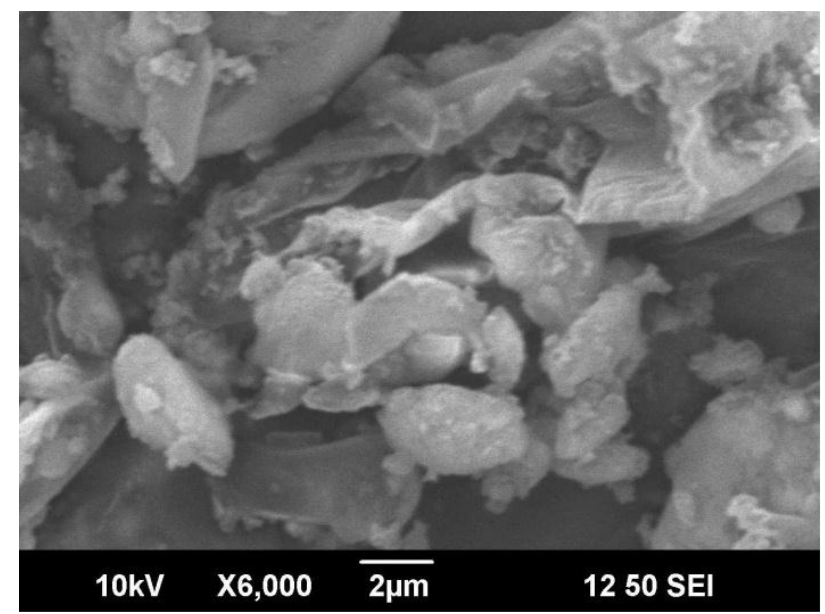

Rifapentine bulk drug

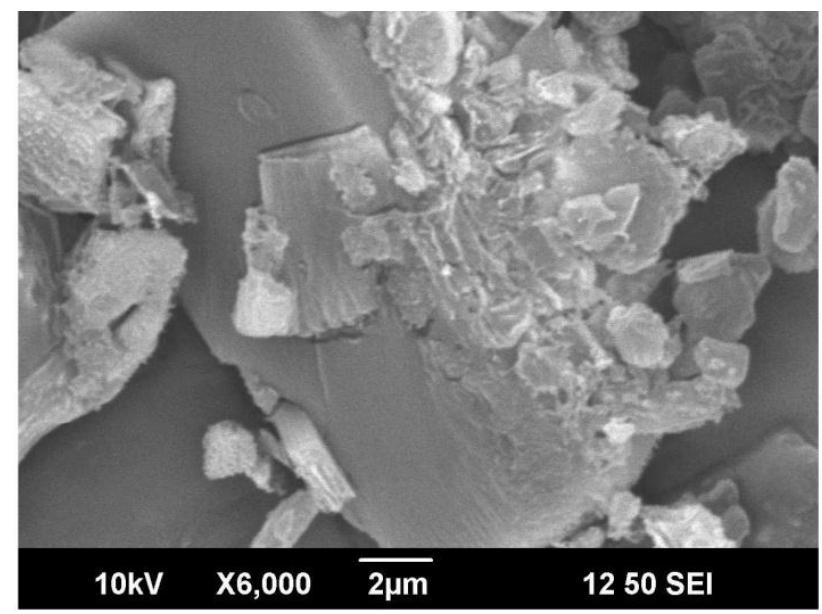

SP8 (optimized solid dispersion)

Figure 14: SEM of Rifapentine bulk drug and SP8 (optimized solid dispersion)

\section{CONCLUSION}

All solid dispersions prepared by kneading method and solvent evaporation method shows increment in solubility as well as drug release profile as compare to physical mixtures with low standard deviation values in percent drug content ensured uniformity of drug content in each batch. The solubility was enhanced from $0.62 \mathrm{mg} / \mathrm{ml}$ (plain rifapentine) to $6.34 \mathrm{mg} / \mathrm{ml}$ (SP8) by using hydrophilic carrier in solid dispersion formulation by using simple solvent evaporation technique. Figure 4 and 6 shows the in vitro dissolution profiles of rifapentine from SDs containing various ratios of drug to PVP-K30 in which max \% drug release was obtained in batch SP8 (93.91 \pm 0.22 ). Figure 5 and 7 shows the in vitro dissolution profiles of rifapentine from SDs containing various ratios of drug to HPMC in which max \% drug release was obtained in batch SH8 $(90.36 \pm 0.22)$. In contrast, the dissolution rate of rifapentine from all PVP-K30 and

\section{REFERENCES}

1. Riva E., Merati R., Cavenaghi L., High-performance liquid chromatographic determination of rifapentine and its metabolite in human plasma by direct injection into a shielded hydrophobic phase column. Journal of Chromatography, 1991, 553(1-2), 3540.

2. Emary W.B., Paul C.T., Mathews B., Kay H., Disposition and Metabolism of Rifapentine, a Rifamycin Antibiotic, in Mice, Rats, and Monkeys. Drug Metabolism and Disposition, 1998, 26(8), 725-731.

3. Zhou K., Jun L., Jianhong L., Jin Y., Crystal Growth, Structure and Morphology of Rifapentine Methanol Solvate. Chinese Journal of Chemical Engineering, 2012, 20(3), 602-607.

4. Zhou K., Jun L., Jianhong L., Dongsheng Z., Crystal modification of rifapentine using different solvents. Frontiers of Chemical Engineering in China, 2010, 4(1), 65-69.

5. Kapil K., Shiva S., Jain D.A., Enhancement of solubility and dissolution rate of rifapentine by melt granulation technique. International Journal of Pharmacy \& Life Sciences, 2012, 3(3), 1503-1506.

6. Tam C.M., Chan S.L., Lam C.W., Leung C.C., Kam K.M., Morris J.S., Mitchison D.A., Rifapentine and isoniazid in the continuation phase of treating pulmonary tuberculosis: initial report. American Journal of Respiratory and Critical Care Medicines, 1998, 157(6), 1726-1733.
HPMC SDs was significantly higher than that of rifapentine alone. Physical mixture of PVP-K30 and HPMC also improves the dissolution profile of rifapentine due to its hydrophilic nature but not such an extent as by kneading method and solvent evaporation method. In the solid dispersion state because of kneading of rifapentine with the polymers, it was converted into amorphous form or change in crystal form may changes the different physicochemical properties, as per the XRD graph of plane drug and solid dispersion proving. The results of scanning electron microscopy also show that the changes occurred in the morphology and nature of particles from plane drug to solid dispersion. The solid dispersion with PVP-K30 and HPMC have been prepared by different methods in different ratios and found that solvent evaporation (SP8) shows the better enhancement of solubility in comparison to the others.

7. James K., Solubility and related properties, Vol. 28, Marcel Dekker Inc., Newyork, 986, 127 -146, 355 - 395.

8. Modi A. and Tayade P.A., Comparative solubility enhancement profile of valdecoxib with different solubilization approaches. Indian J. of Pharm. Sciences, 2007, 69: 274 - 278.

9. Yadav V.B., Enhancement of solubility and dissolution rate of Rifampicin by melt granulation technique. J. Pharm, Res., 2009, 2: $230-235$.

10. Nagasamy Venkatesh D., Dissolution Enhancement of Domperidone Using Water Soluble Carrier By Solid Dispersion Technology International Journal of Pharmaceutical Sciences and Nanotechnology, 2008, 1:221-236.

11. Higuchi T., Shih F.L., Kimura T., Rytting J.H., Solubility determination of barely aqueous soluble organic solids. J. Pharm. Sci., 1979, 68, 1267-1272.

12. Rao M., Mandage Y., Characterization of Solid Dispersions of Simvastatin with PVP K30 and Poloxamer 188, Ind J Pharm Edu Res, 2011, 45(2):192-196.

13. Srikanth, M., "Dissolution Rate Enhancement of Poorly Soluble Bicalutamide Using Bcyclodextrin Inclusion Complexation". International Journal of Pharmacy and Pharmaceutical Sciences, 2010, 2 (1):191-198. 